\title{
Realization and Experimental Analysis of Electron Beam Surfi-Sculpt on Ti-6Al-4V Alloy
}

\author{
Wang Xichang ${ }^{1,2}$, Guo Enming ${ }^{2}$, Gong Shuili², Li Bin ${ }^{1}$ \\ ${ }^{1}$ Huazhong University of Science \& Technology, Wuhan 430074, China; ${ }^{2}$ Science and Technology on Power Beam Processes Laboratory, \\ Beijing Aeronautical Manufacturing Technology Research Institute, Beijing 100024, China
}

\begin{abstract}
The realization method of electron beam surfi-sculpt on Ti-6Al-4V alloy was studied. Surfi-sculpt could be obtained by tailored scanning waveform based on the new scanning control system, and then the protrusions with no less than $2 \mathrm{~mm}$ in height were got on the metal surface. By the method, the different profiles of the protrusions were tried from different scanning waveforms and frequencies and the microstructure of protrusions was analyzed. The results show that six lines meeting waveform is the best way to get protrusions, while proper frequency is also a key factor to realize the surfi-sculpt process. The microstructure of the protrusion could be divided into four parts, which are edge zone, central zone, HAZ and base metal.
\end{abstract}

Key words: electron beam surfi-sculpt; scanning waveform and frequency; protrusion; six lines meeting; microstructure

Electron beam surfi-sculpt ${ }^{[1,2]}$ is a novel metal surface processing technology, by which customized textured morphology on a metal surface can be produced by controlling process parameters and scanning route of the electron beam. Currently the height of protrusions realized during electron beam surfi-sculpt process could be got from $10 \mu \mathrm{m}$ up to 20 $\mathrm{mm}$. This technology can be potentially applied in the fields of dissimilar materials joining between metal and composite ${ }^{[3,4]}$ and surface sculpting for its high efficiency.

There are differences between an electron beam surfi-sculpt and a traditional electron beam processing technology. Other than vacuum chamber, vacuum system, electron beam gun and high voltage power supply, the electron beam surfi-sculpt requires a specially tailored scanning control system to realize fast beam deflection in the process ${ }^{[5]}$. Besides an electron beam gun with lower power and higher beam quality is preferred.

In this paper, combined with an in-hand electron beam machine, a new electron beam processing technique based on image-scanning was built, by which protrusions with no less than $2 \mathrm{~mm}$ in height on metal surface can be produced by the developed new scanning control system and optimized scanning waveform. Protrusions by different process parameters were obtained, and microstructures of protrusions were analyzed.

\section{Experiment}

\subsection{Forming process}

Firstly, to realize fast beam deflection by an electromagnetic field, as shown in Fig.1, electron beam is emitted from EB gun on top of the machine and deflected upon appearing in the middle of deflection coil linked arbitrary signal generator. By fast deflection, the electron beam can stop in different positions. Secondly, to move the beam according to special rule, proper speed and energy, then the molten materials will be built up behind the beam by the effect of vapour pressure and surface tension. Last by repeating this process many times at the same site, the protrusions will be grown. They are shown in Fig.2 and Fig.3.

\subsection{Hardware and software}

Electrons can be quickly deflected in magnetic field by Lorenz force since they have minute mass and negative electricity. A specifically designed scanning control system is required to realize the electron beam surfi-sculpt technology, including fast-response deflection coils, multi-function signal generator with high precision. The principle of this system is shown in Fig.4.

\footnotetext{
Received date: April 08, 2013

Foundation item: The National Nature Science Foundation of China (50975268, 50935008); Aeronautical Science Foundation of China (2008ZE25010)

Corresponding author: Wang Xichang, Candidate for Ph. D., Senior Engineer, Science and Technology on Power Beam Processes Laboratory, Beijing Aeronautical Manufacturing Technology Research Institute, Beijing 100024, P. R. China, Tel: 0086-10-85707580, E-mail: xichangw@sina.com 


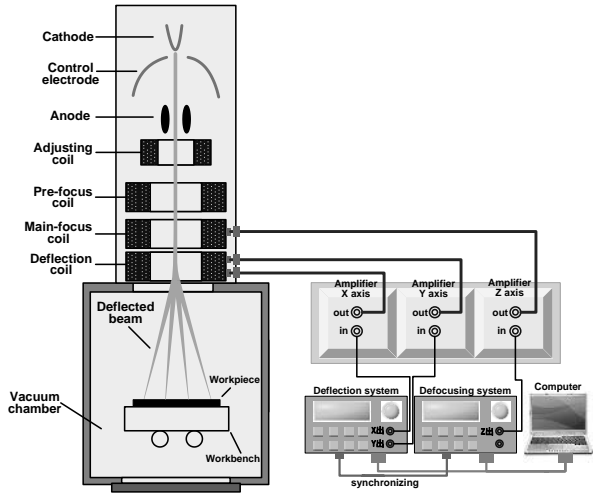

Fig.1 Electron beam surfi-sculpt machine

错误!

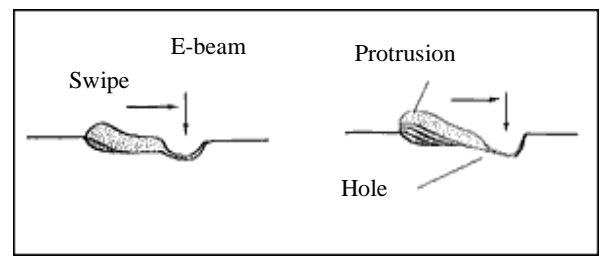

错误!

Fig.2 Forming process

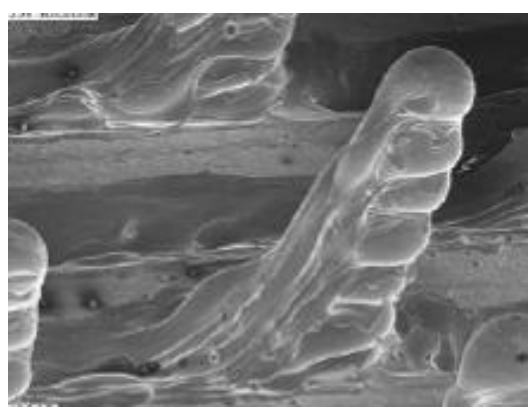

Fig.3 Protrusions

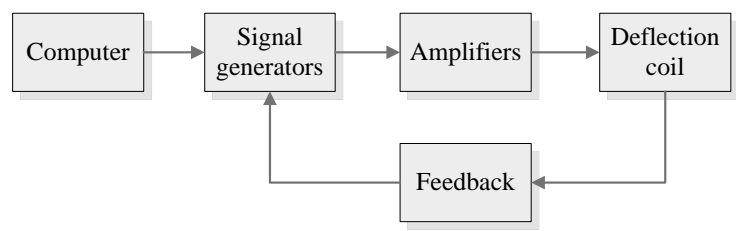

Fig.4 Principle of control system

In the control system, a computer is adopted as a host computer to set up process parameters and to edit data from scanning waveform. The data from the computer are transformed into analog signals, which are sent to a deflection coil after being processed by amplifier. The deflection coil is driven by a analog signals and creates magnetic fields in different directions. In the combined magnetic fields, the electron beam can be deflected according to designed pattern and creates tailored scanning routes. If the focus current in focus coil can be adjusted at the same time, then 3D scanning control can be realized, thus producing better protrusion morphology with more variety.

Of course, special soft can also be designed to edit waveform. By this way, edited waveform file may be imported conveniently into host computer soft.

\section{Results and Discussion}

\subsection{Results of different waveforms}

Waveforms are important keys on the surfi-sculpt processing, which could move the electron beam according to a special route under the control of electromagnetic field. Different waveforms may influence differently the developing of protrusions, including shape, time, height, and so on. In the paper, different types of waveforms were adopted to try the surfi-sculpt experiments. Table 1 shows processing parameters. Ti-6Al-4V alloy was tried in the paper.

Fig. 5 shows different profiles of the protrusions obtained from the experiments according to different types of waveforms. It is shown that the different profiles of the protrusions can be obtained by different waveforms. Waveforms change the moving tracks of electron beam, while protrusions will be grown behind the beam. They will be also developed quickly in the places of the beams superposition. Fig.5a and Fig.5b reveal deeper grooves near the protrusions for few lines meeting. Fig.5c shows shorter protrusions for longer time effect. The best protrusions could be seen from Fig.5d.

\subsection{Results of different frequencies}

According to the results of Fig.5, the waveform of six lines meeting was carried out in this part, and only their frequencies were changed. The processing parameters are shown in Table 2.

Fig. 6 shows the different profiles of the protrusions are obtained by different waveforms frequencies. The protrusions in Fig.6a are much wider for the low moving speed of electron beam under a low frequency, while Fig.6c reveals much shorter protrusions for the high speed of beam under a higher frequency. The best of results could be seen from Fig.6b for a proper speed of beam.

\subsection{Analysis of processing parameters}

Actually many processing parameters influence the

Table 1 Processing parameters

\begin{tabular}{cccccc}
\hline $\begin{array}{c}\text { Accelerating } \\
\text { voltage/kV }\end{array}$ & $\begin{array}{c}\text { Beam } \\
\text { current/mA }\end{array}$ & Waveform & Time/s & $\begin{array}{c}\text { Height/ } \\
\mathrm{mm}\end{array}$ & $\begin{array}{c}\text { Figure } \\
\text { No. }\end{array}$ \\
\hline 150 & 2 & One line & 60 & 1.9 & Fig.5a \\
150 & 2.6 & Three lines & 60 & 2.0 & Fig.5b \\
150 & 2.2 & Four lines & 100 & 1.8 & Fig.5c \\
150 & 2.1 & Six lines & 60 & 2.1 & Fig.5d \\
\hline
\end{tabular}



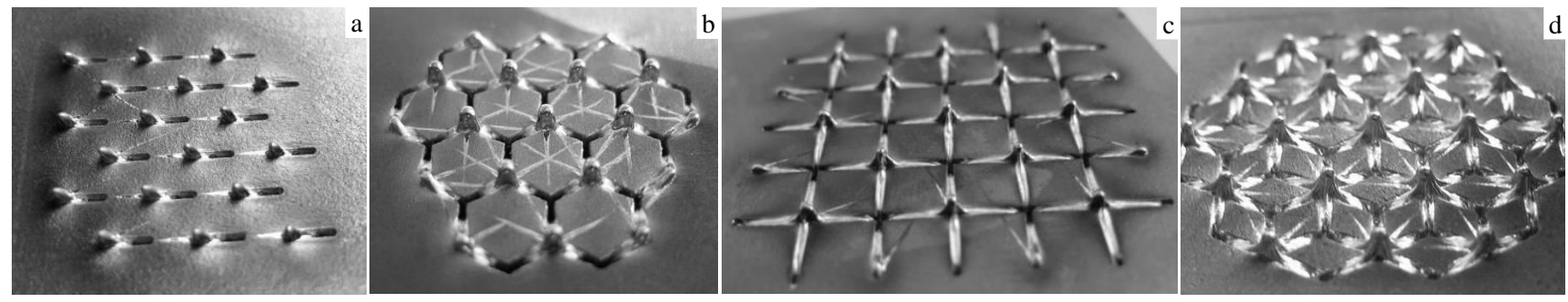

Fig.5 Profiles of protrusions from different waveforms: (a) one line, (b) three lines, (c) four lines, and (d) six lines

Table 2 Processing parameters

\begin{tabular}{cccccc}
\hline $\begin{array}{c}\text { Accelerating } \\
\text { voltage/kV }\end{array}$ & $\begin{array}{c}\text { Beam } \\
\text { current/mA }\end{array}$ & $\begin{array}{c}\text { Frequency/ } \\
\mathrm{Hz}\end{array}$ & $\mathrm{sime/}$ & Height/ & Figure \\
$\mathrm{mm}$ & No. \\
\hline 150 & 2 & 0.25 & 60 & 1.0 & Fig.6a \\
150 & 2 & 0.5 & 60 & 2.0 & Fig.6b \\
150 & 2 & 0.75 & 60 & 0.8 & Fig.6c \\
\hline
\end{tabular}

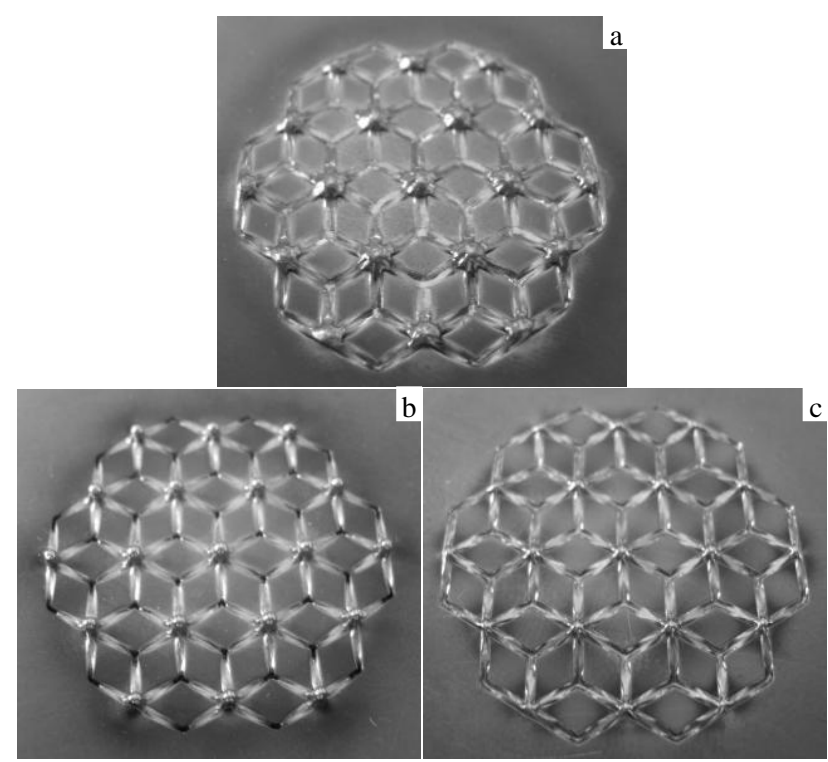

Fig.6 Profiles of protrusions from different frequencies: (a) $0.25 \mathrm{~Hz}$, (b) $0.5 \mathrm{~Hz}$, and (c) $0.75 \mathrm{~Hz}$

developing of protrusions, but the key factors are beam current, time, waveform, and frequency, which determine the heat input value in the route of moving beam. The larger the beam current value, the more the time, the higher the protrusions will be, but too large beam current value or too much time will decrease the height of the protrusions. Waveform and frequency determine the realization of surfi-sculpt processing. The proper values could increase the height and forming speed of protrusions, while improper values will not pile molten material and not realize surfi-sculpt.

\subsection{Microstructure of the protrusion}

Optical micrographs of protrusion fusion zone and heat affected zone are presented in Fig.7. Four different zones, which include base metal, heat affected zone (HAZ), central zone, and edge zone can also be analyzed according to different cooling rates. The optical microstructure of base metal, as shown in Fig.8a, consists of primary $\alpha$ phase in a matrix of transformed $\beta$. Fig. $8 \mathrm{~b}$ reveals the microstructures of the interface of protrusion fusion zone and heat affected zone. The heat affected zone shows a mixture of martensitic $\alpha$, acicular $\alpha$ and primary $\alpha$ in all conditions. The formation of the needle grains is due to the fast cooling rate during electron beam surfi-sculpt process, which can also be seen from Fig. $8 \mathrm{c}$ and Fig.8d. Fig.8c shows the serrate and regular plate-shaped

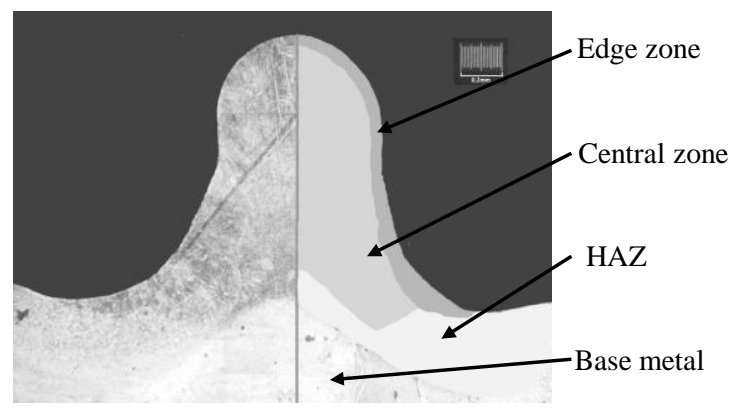

Fig.7 Optical micrograph of protrusion area including four zones $(\times 200)$

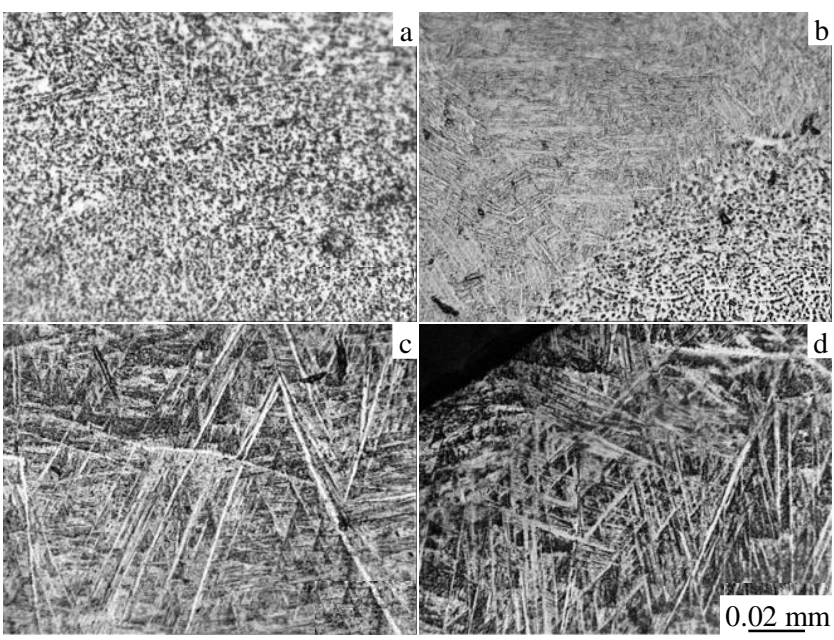

Fig.8 Microstructures of different protrusion areas: (a) base metal, (b) heat affected zone (HAZ), (c) central zone, and (d) edge zone 
$\alpha$ structures of central zone. The plate-like $\alpha$ is due to the slower cooling rate inside of the protrusions for repeating melting and piling many times at the same site. Fig. $8 d$ shows similar microstructure of edge zone, just out of order and smaller for slower cooling rate.

\section{Conclusions}

1) Protrusions can be obtained on the surface of Ti-6Al-4V alloy during surfi-sculpt process by a new scanning control system and different waveforms.

2) Different waveforms and frequencies will influence the forming results of protrusions. Six lines meeting waveform is the best of way to get protrusions, while a proper waveform frequency will determine directly the parameters of the protrusions.

3) The microstructures of protrusions are different from the base metal. After melting, flowing and solidification, the serrate and regular plate-shaped $\alpha$ structures can be also seen inside the protrusion.

\section{References}

1 Wang Xichang, Gong Shuili, Guo Enming et al. Advanced Materials Research[J], 2012, 418-420: 772

2 Buxton A L, B G I Dance. Proc of 4th International Surface Engineering Congress(ISEC2005)[C]. USA, Minnesota: ISEC, 2005

$3 \mathrm{Tu}$ W, Wen P H, Hogg P J et al. Composites Science and Technology[J], 2011, 71: 868

$4 \mathrm{Tu}$ W, Wen P H, Hogg P J et al. Composites Materials Science [J], 2010, 48: 481

5 Wang Xichang, Guo Enming, Gong Shuili et al. Rare Metal Materials and Engineering[J], 2011, 40(10): 292 (in Chinese)

\title{
TC4 钛合金电子束毛化的实现方法和试验分析
}

\author{
王西昌 ${ }^{1,2}$, 郭恩明 ${ }^{2}$, 巩水利 ${ }^{2}$, 李 斌 ${ }^{1}$
}

(1. 华中科技大学, 湖北 武汉 430074)

(2. 北京航空制造工程研究所 高能束流加工重点实验室, 北京 100024)

\begin{abstract}
摘 要: 提出了一种钠合金电子束毛化技术实现方法。借助于新型电子束扫描控制系统，通过扫描波形的特殊设计，可以实现电子束毛 化技术，从而在金属表面产生高约几毫米的毛刺。利用这种实现方法，通过选取不同的扫描波形和扫描频率获得了各种不同的毛刺形貌， 并进行了毛刺的组织分析。结果表明: 六边汇聚型扫描波形毛化效果最理想, 而合适的扫描频率同样也是产生毛化形貌的关键。毛刺的 微观组织区域分成了边缘区、中心区、热影响区和母材。
\end{abstract}

关键词: 电子束毛化; 扫描波形和频率; 毛刺; 六边型汇聚; 微观组织

作者简介: 王西昌, 男, 1979 年生, 博士生, 高级工程师, 北京航空制造工程研究所高能束流加工重点实验室, 北京 100024 , 电话: 010-85701580, E-mail: xichangw@ sina.com 